\title{
Positive Dendritic Effect in DNA/Porphyrin Composite Photocurrent Generators Containing Dendrimers as the Stationary Phase
}

Shin Ogasawara, Atsushi Ikeda, * and Jun-ichi Kikuchi

Graduate School of Materials Science, Nara Institute of Science and Technology, Takayama, Ikoma, Nara 630-0192, Japan.; Fax: +81-0743-72-6099; Tel: +81-0743-72-6091

Supporting Information 
Table S1. Surface Coverage of Dendrimers

\begin{tabular}{cccc}
\hline & $\Delta F^{a}$ & $\begin{array}{c}\text { Surface coverage of dendrimer } \\
/ \mathrm{mol} \mathrm{cm}^{-2 b}\end{array}$ & $\begin{array}{c}\text { Surface coverage of amino } \\
\text { moieties } / \mathrm{mol} \mathrm{cm}^{-2 b}\end{array}$ \\
\hline G1 & $10.3 \pm 1.9$ & $(7.23 \pm 1.32) \times 10^{-12}$ & $(1.01 \pm 0.18) \times 10^{-10}$ \\
G2 & $19.7 \pm 2.4$ & $(6.04 \pm 0.72) \times 10^{-12}$ & $(1.81 \pm 0.22) \times 10^{-10}$ \\
G3 & $28.7 \pm 6.9$ & $(4.15 \pm 1.01) \times 10^{-12}$ & $(2.57 \pm 0.62) \times 10^{-10}$ \\
G4 & $42.7 \pm 9.0$ & $(3.00 \pm 0.64) \times 10^{-12}$ & $(3.78 \pm 0.80) \times 10^{-10}$ \\
\hline
\end{tabular}

${ }^{a}$ Each experiment was performed three times. ${ }^{b}$ Estimated from $\Delta F$ on an ITO electrode. ${ }^{11}$

Table S2. Surface Coverage of DNA

\begin{tabular}{lcc}
\hline & $\Delta F^{a}$ & Surface coverage of DNA $/ \mathrm{mol} \mathrm{cm}^{-2 b}$ \\
\hline G1-DNA & $27.7 \pm 2.6$ & $(1.03 \pm 0.10) \times 10^{-10}$ \\
G2-DNA & $53.3 \pm 1.9$ & $(1.99 \pm 0.07) \times 10^{-10}$ \\
G3-DNA & $73.7 \pm 5.0$ & $(2.75 \pm 0.19) \times 10^{-10}$ \\
G4-DNA & $82.7 \pm 3.7$ & $(3.09 \pm 0.14) \times 10^{-10}$ \\
\hline
\end{tabular}

${ }^{a}$ Each experiment was performed three times. ${ }^{b}$ Estimated from $\Delta F$ on an ITO electrode. ${ }^{11}$

Table S3. Surface Coverage of 1

\begin{tabular}{lcc}
\hline & $\operatorname{Abs}_{436}{ }^{a}$ & Surface coverage of $\mathbf{1} / \mathrm{mol} \mathrm{cm}^{-2 b}$ \\
\hline G1-DNA-1 & $1.03 \times 10^{-2}$ & $1.40 \times 10^{-11}$ \\
G2-DNA-1 & $1.36 \times 10^{-2}$ & $1.85 \times 10^{-11}$ \\
G3-DNA-1 & $1.66 \times 10^{-2}$ & $2.26 \times 10^{-11}$ \\
G4-DNA-1 & $1.91 \times 10^{-2}$ & $2.60 \times 10^{-11}$ \\
\hline
\end{tabular}

${ }^{a}$ Absorbance at $436 \mathrm{~nm}$ on an ITO electrode. ${ }^{b}$ Estimated from absorption spectra on an ITO electrode.

Table S4. Photocurrent density and quantum yield

\begin{tabular}{lcc}
\hline & Photocurrent density $/ \mathrm{nA} \mathrm{cm}^{-2 a}$ & Quantum yield $/ \%$ \\
\hline G1-DNA-1 & 8.5 & 0.21 \\
G2-DNA-1 & 14.9 & 0.28 \\
G3-DNA-1 & 26.9 & 0.40 \\
G4-DNA-1 & 77.5 & 1.04 \\
\hline
\end{tabular}

${ }^{a}$ Illumination: $440 \mathrm{~nm}$; input power: $1 \mathrm{~mW} \mathrm{~cm}{ }^{-2}$; applied potential: $0.4 \mathrm{~V}$ vs. $\mathrm{Ag} / \mathrm{AgCl} ; 0.1 \mathrm{M} \mathrm{Na}_{2} \mathrm{SO}_{4}$ solution containing $0.05 \mathrm{M}$ TEOA. 


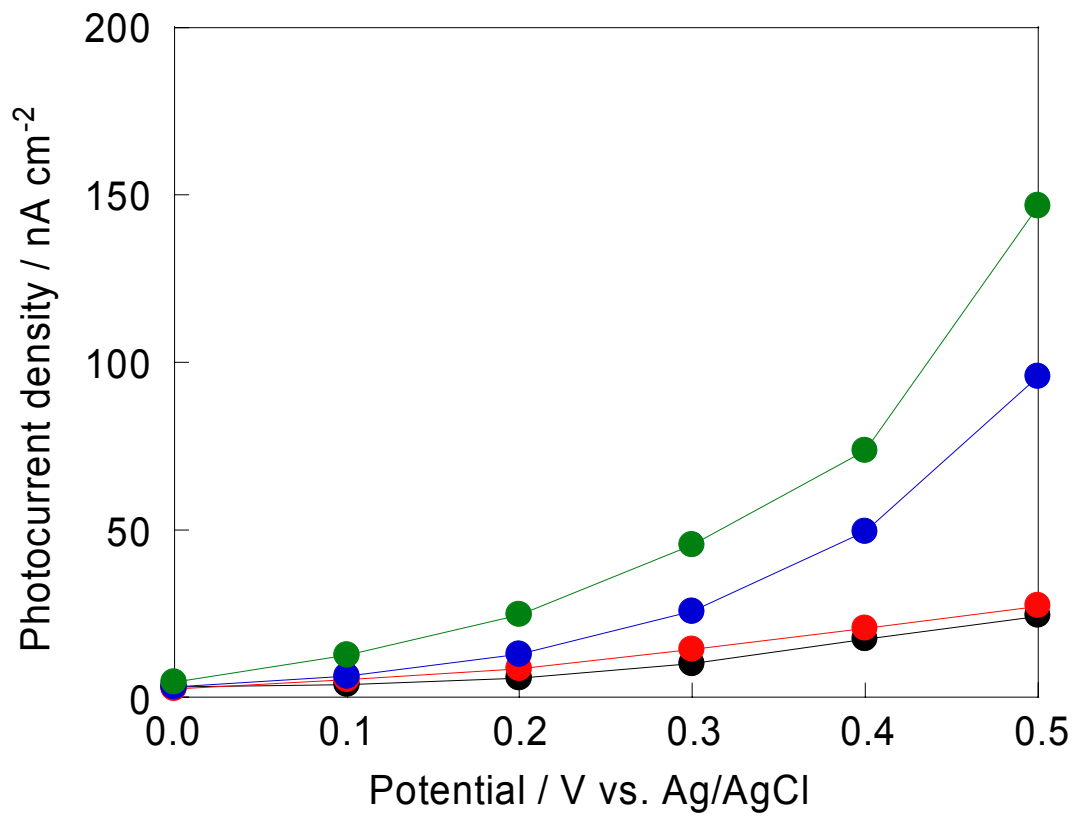

Figure S1. Photocurrent vs. bias potential applied to the G1-DNA-1 (black), G2-DNA-1 (red), G3DNA-1 (blue), and G4-DNA-1 (green) systems on an ITO electrode; illumination: $440 \mathrm{~nm}$; input power: $1 \mathrm{~mW} \mathrm{~cm}{ }^{-2} ; 0.1 \mathrm{M} \mathrm{Na}_{2} \mathrm{SO}_{4}$ solution containing 0.05 M TEOA. 


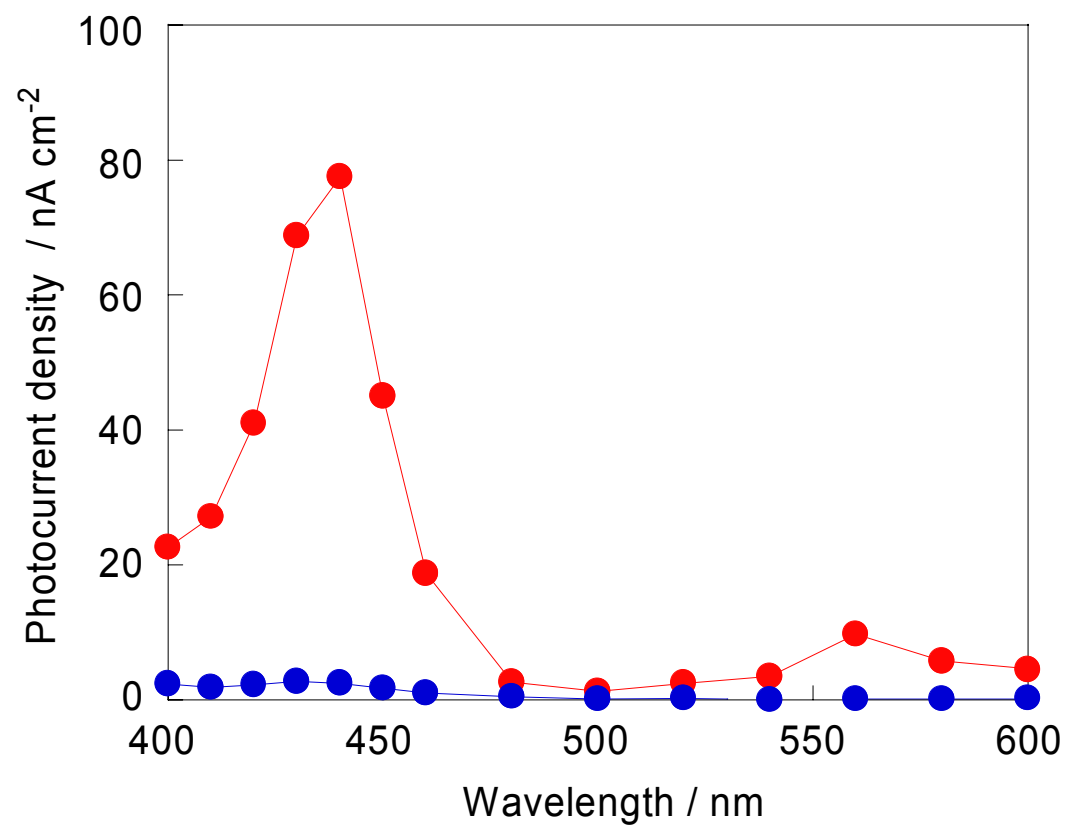

Figure S2. Action spectra of the G4-DNA-1 system in the presence (red line) and absence (blue line) of TEOA; input power: $1 \mathrm{~mW} \mathrm{~cm}{ }^{-2}$; applied potential: $0.4 \mathrm{~V}$ vs. $\mathrm{Ag} / \mathrm{AgCl} ; 0.1 \mathrm{M} \mathrm{Na}_{2} \mathrm{SO}_{4}$ solution containing $0.05 \mathrm{M}$ or $0.00 \mathrm{M}$ TEOA. 


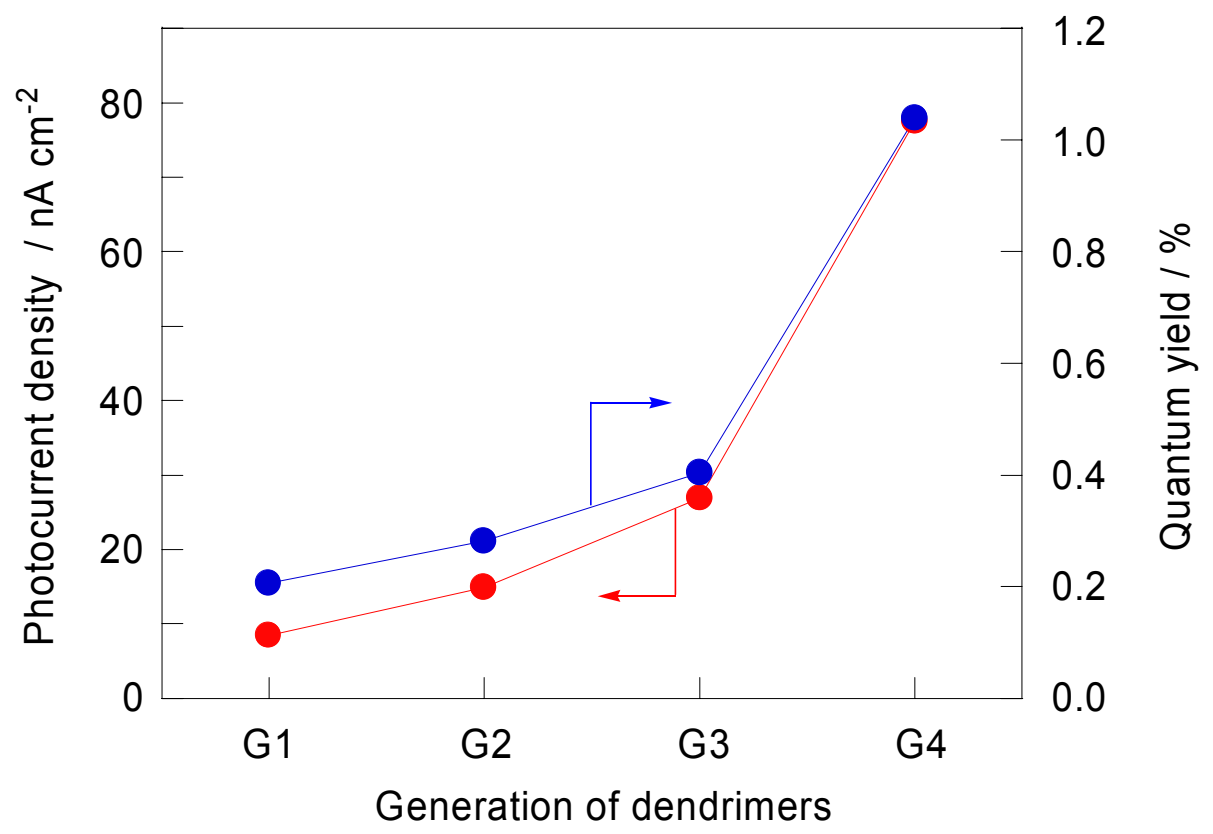

Figure S3. Plots of the photocurrent and the quantum yield at $440 \mathrm{~nm}$ as functions of the generation of the dendrimer; input power: $1 \mathrm{~mW} \mathrm{~cm}{ }^{-2}$; applied potential: $0.4 \mathrm{~V}$ vs. $\mathrm{Ag} / \mathrm{AgCl} ; 0.1 \mathrm{M} \mathrm{Na}_{2} \mathrm{SO}_{4}$ solution containing $0.05 \mathrm{M}$ TEOA. 


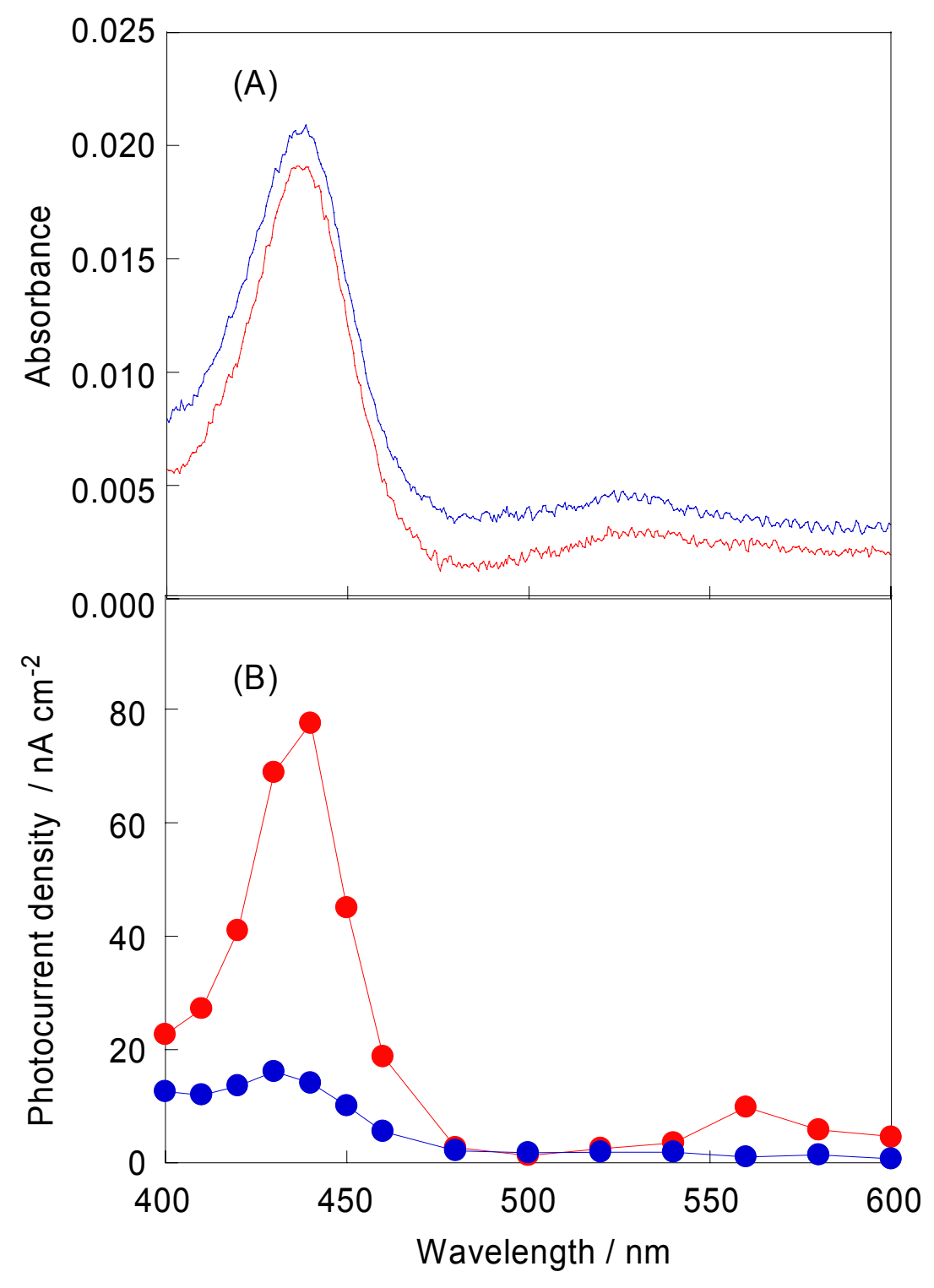

Figure S4. (A) Electronic absorption spectra and (B) action spectra of the G4-DNA-1 (red line) and PAH-DNA-1 (blue line) systems on an ITO electrode; illumination: $440 \mathrm{~nm}$; input power: $1 \mathrm{~mW} \mathrm{~cm}^{-2}$; applied potential: $0.4 \mathrm{~V}$ vs. $\mathrm{Ag} / \mathrm{AgCl} ; 0.1 \mathrm{M} \mathrm{Na}_{2} \mathrm{SO}_{4}$ solution containing 0.05 M TEOA. 


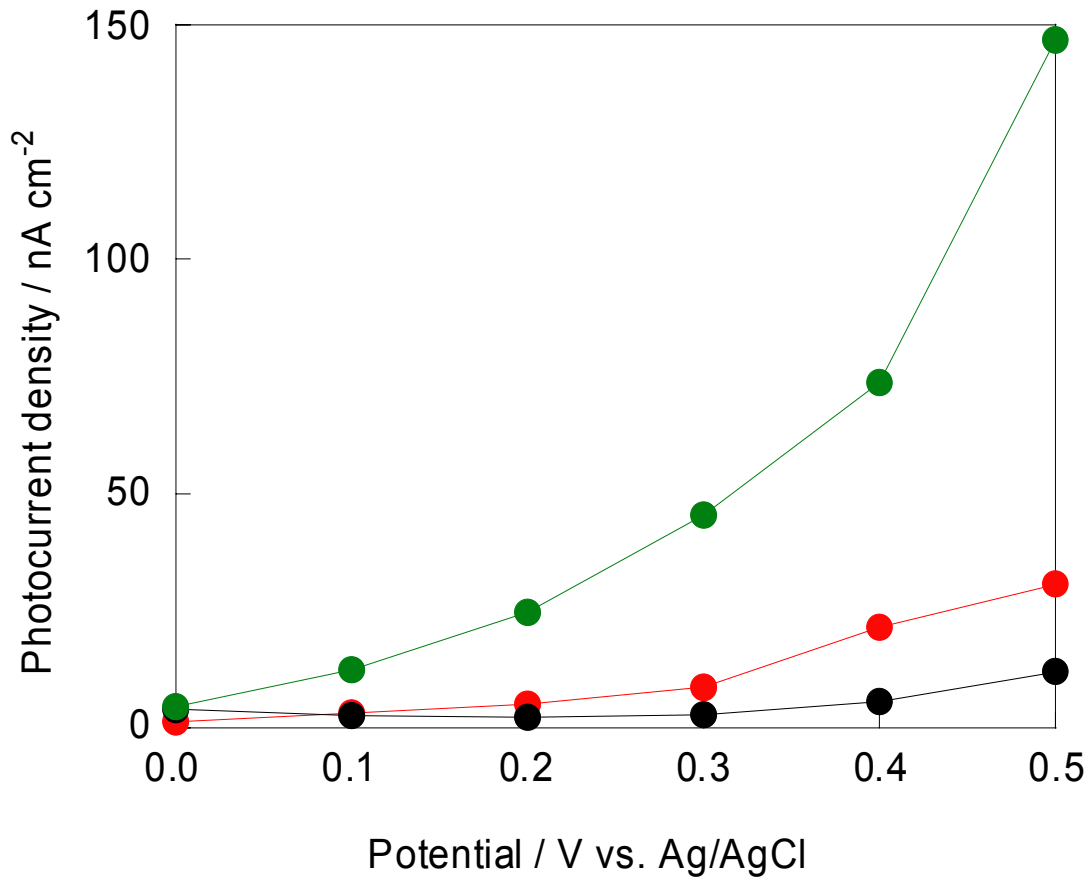

Figure S5. Photocurrent vs. bias potential applied to the G1-PVS-1 (black), G4-PVS-1 (red), and G4-DNA-1 (green) systems on an ITO electrode; illumination: $440 \mathrm{~nm}$; input power: $1 \mathrm{~mW} \mathrm{~cm}{ }^{-2} ; 0.1$ $\mathrm{M} \mathrm{Na}_{2} \mathrm{SO}_{4}$ solution containing $0.05 \mathrm{M}$ TEOA. 